\title{
Das escolhas que fiz: implicações etnográficas na pesquisa com crianças
}

Ileana Wenetz ${ }^{*}$

Resumo: A partir de pesquisar gênero e sexualidade nas brincadeiras do recreio escolar, procuro descrever o processo de inserção como pesquisadora numa escola pública, narrando as diferentes decisóes tomadas que permitiram refletir sobre um olhar de uma estrangeira num contexto brasileiro. Realizei uma etnografia em duas turmas: uma segunda e uma terceira série do Ensino Fundamental. Nesses grupos, realizei observações em diferentes momentos do quotidiano escolar, particularmente o recreio, e entrevistas com crianças. Os resultados das escolhas metodológicas permitiram um maior aprofundamento dos significados que as crianças atribuem ao seu dia a dia e do fazer do etnógrafo, além da observação de que, no espaço do recreio, dentre outros momentos na escola, acontecem aprendizagens tidas como não oficiais e não intencionais, através das quais, crianças aprendem a ser meninos e a ser meninas.

Palavras-chave: etnografia; crianças; metodologia; gênero.

The choices I have made: ethnographic implications in researches with children

Abstract: From a survey on gender and sexuality in games played at the school playground during the break, I try to describe the process of inclusion as a researcher in a public school, narrating the various taken decisions that allowed reflection from the point of view of a foreigner in a Brazilian context. I carried out an ethnographic work in groups from the first to the fourth grade, focusing on a second and a third grade groups from the elementary school. In these groups, observations were made at different times of the daily school life, particularly during the school break at the playground and in interviews with the children. The results of the methodological choices permitted a further investigation on the meanings children give to their daily routine and on the ethnographer's task, besides allowing the observation that at the recreation area during the school break non-official and non-intentional learning occurs through which, among other moments in school, children learn how to behave as boys or girls.

Key words: ethnography; children; methodology; gender.

* Doutoranda na Escola de Educação Física (EsEF), membro do Grupo de Estudos Socioculturais em Educação Física (GESEF) e do Grupo de Estudos de Educação e Relações de Gênero (GEERGE), Universidade Federal do Rio Grande da Sul (UFRGS), Brasil. Bolsista da Capes/CNPqIEL Nacional-Brasil. ilewenetz@gmail.com 


\section{Algumas considerações iniciais}

Neste artigo, pretendo abordar as escolhas metodológicas desenvolvidas na pesquisa, caracterizando o modo de 'olhar, observar e/ou refletir' a partir da etnografia. Além de discorrer sobre os instrumentos de investigação utilizados, procuro descrever meu processo de inserção na escola, narrando as diferentes decisões teórico-metodológicas relacionadas com minha percepção de estrangeira em um ambiente escolar brasileiro. Assim, aprofundarei vários sentidos do ser estrangeiro, pois era uma estrangeira na escola, uma pesquisadora entre os/as professores/as, uma adulta entre as crianças e uma não brasileira entre os/as brasileiros/as. É importante ressaltar que, em vários momentos, essas diversas formas de ser estrangeira atravessavam-se e sobrepunham-se.

Para dar conta deste 'fazer' metodológico, apoio-me na abordagem dos Estudos Culturais e de Gênero ${ }^{2}$, procurando privilegiar seus aspectos metodológicos, na tentativa de compreender e problematizar os sentidos sociais atribuídos ao gênero e ao corpo nas práticas corporais que permeiam o recreio da primeira à quarta série de uma escola pública de Porto Alegre. Para tanto, escolhi a etnografia, pois permite que as questóes sejam respondidas no transcorrer do próprio processo investigativo.

Essa articulação admite entender como se configuram modos diferentes de observar o mundo, que possibilitam também formas distintas de questionar/pensar sobre nossas escolhas e nossos objetos de pesquisa, sem que se tornem fixos e inalteráveis.

\section{A etnografia}

Para muitos/as pesquisadores/as, a etnografia é entendida como "um conjunto de concepçôes e procedimentos utilizados tradicionalmente pela antropologia para fins de conhecimento científico da realidade social" (Knauth; Ceres; Agra Hassen, 2000, p. 53, grifo meu). Nesse sentido, o/a pesquisador/a procura observar e descrever detalhadamente o comportamento humano. Para outros/as, a etnografia é entendida, mais do que como método científico, como uma arte em que o/a etnógrafo/a precisa aguçar suas observaçóes, refinar o ouvido, ter sensibilidade emocional, penetrar nas vidas de várias e diferentes pessoas, tentando perceber

1. Esclareço que uso o recurso itálico para destacar aquelas palavras que implicam um desacordo com o sentido tradicional que carregam; aspas simples para palavras que eu quero destacar.

2. Gênero: engloba processos de construção social, cultural e linguística em que se diferenciam homens e mulheres, ocorrendo ao longo da vida dos sujeitos, em interação com diversas circunstâncias em que estes aprendem a tornar-se homens e mulheres de um determinado modo. Essas aprendizagens, que incluem dimensões sociais e culturais, passam também pelo corpo (Nicholson, 2000; Louro, 2000; Meyer, 2003). 
como se sentem. Enquanto isso, não deve esquecer-se de colocá-las objetivamente, de poder expressar-se, de recriar situações, de ter capacidade de contar uma história, construindo uma narrativa daquilo que se observou, estando lá entre aquelas pessoas, naquele local específico (Woods, 1995).

Assim, o estudo etnográfico possibilita a análise 'por dentro' na procura daquilo que se constitui como particular, relacionando-o com a experiência do/a investigador/a de campo, o que permite uma maior proximidade entre este/a e os sujeitos integrantes daquele contexto particular. Segundo Geertz, a etnografia é entendida como uma "descrição densa", já que o/a etnógrafo/a tem que trabalhar com complexas estruturas conceptuais que muitas vezes se apresentam inter-relacionadas, superpostas, misturadas e heterogêneas, simultaneamente diferentes e estranhas entre si. Ainda, o autor diz que, ao observar-se a cultura, é possível defini-la como um contexto que pode ser descrito (acontecimentos sociais, comportamentos, instituições ou processos) de uma maneira inteligível, ou seja, com densidade (1989a, p. 24).

A etnografia, entendida tanto como arte quanto como disciplina científica, consiste em um conjunto de características, como saber 'ver', saber 'estar' com outros e consigo mesmo e retraduzir aquilo que se percebeu, a interpretação por meio da escrita de um terceiro (Winkin, 1998). Segundo Geertz (1989b, p. 63), o trabalho de articular aquilo que se vivencia no local implica "uma presença do 'Lá' em um texto elaborado 'Aqui'”.

Continuando com os argumentos dos benefícios da etnografia, considero importante destacar sua relação com a temática do gênero. Vários artigos trazem articulaçōes entre etnografia e gênero (Swain, 2006; Kelle, 2000; Goodwin, 2002; Ronald, 2003; Epstein et al., 2001; Boyle et al., 2003). Ainda posso afirmar que os estudos etnográficos estão fundamentados na característica de observação detalhada de um contexto particular. O estudo não investiga 'o lugar', e sim 'no lugar', observando-se aqui as relaçōes de gênero 'na escola' e 'no recreio'.

É importante salientar que as análises efetuadas não se focalizaram nos sujeitos, mas antes nos discursos e nas representações que os constituem. Nesse sentido, ao analisar as crianças no recreio escolar, não foram elas o foco de investigação em si, mas através delas foi possível observar os significados presentes nas relaçôes sociais. Desse modo, entendo que os ditos significados configuram as suas relações e as constituem, também, como sujeitos masculinos e femininos.

Para capturar e compreender essas relaçōes no espaço do recreio escolar, realizei o trabalho de campo em uma escola estadual da zona sul da cidade de Porto Alegre, RS. Entendo a escola como uma instituição social inserida num contexto determinado, onde procurei observar as características sociais que constituem essa instituição em particular. Posso entender que a escola é um espaço de especial relevância no processo de socialização dos sujeitos. A instituição encontra-se num bairro que 
poderia ser definido como economicamente mais favorecido ${ }^{3}$, apesar de muitas crianças que moram em suas redondezas não a frequentarem, estudando em escolas particulares situadas no centro da cidade. Muitos/as alunos/as que estudam nessa escola são de bairros economicamente mais desfavorecidos ${ }^{4}$. Isso se deve também a características da região sul da cidade, que, de maneira geral, recebeu nos últimos anos uma população de baixo poder aquisitivo que foi sendo deslocada do centro da cidade para a periferia, estabelecendo-se nesse espaço urbano. ${ }^{5}$

Escolhi o espaço escolar como lócus e, mais especificamente, o recreio, para a realização da pesquisa, por entender que ele constitui um ambiente privilegiado na produção e reprodução de identidades sociais em geral e da identidade de gênero em particular. Compreendo o recreio como sendo livre e espontâneo ${ }^{6}$, diferente da sala de aula, espaço onde os movimentos doslas alunoslas se encontram limitados. Primeiramente, observei crianças de primeira a quarta série; com o passar do tempo, definiram-se duas turmas: uma de segunda série e outra de terceira série.

\section{A inserção na escola}

As escolhas metodológicas encontram-se permeadas de implicações teóricas. Tentarei, neste tópico, relacionar essas escolhas com autores/as da área, buscando justificá-las. A primeira delas referiu-se à definição do espaço concreto para observação. Entretanto, a opção pela escola como lócus não foi uma escolha proposital. Algumas referências bibliográficas apontam que há categorias que o campo nos mostrará, mas também que há outras que estão escolhidas a priori. Além disso, o campo só mostra o que somos capazes de ver dentro da perspectiva que molda nossos olhares. Segundo Rockwell (1987, p.14), "o que de fato se faz no trabalho de campo depende do objeto que se constrói”"

Depois de definir que pretendia estudar gênero na escola e no recreio, minha

3. Destaco aqui que marcadores sociais como 'classe social', religião, raça ou geração não foram concebidos a priori na pesquisa, sendo problematizados conforme o objetivo da pesquisa, questões de gênero e sexualidade.

4. Para poder fazer essa afirmativa, além de me dirigir informalmente a professores/as e funcionárias, busquei informações nas fichas de todos/as os/as alunos/as do turno da manhã da escola.

5. Para mais detalhes, ver Memória dos Bairros: Belém Velho (1994) e Restinga (1997), da Prefeitura de Porto Alegre.

6. Geralmente se expressa no senso comum que o recreio é um espaço de grande liberdade e espontaneidade, mas eu não concordo com isso, pois as crianças são livres na medida em que podem sê-lo. Esses momentos caracterizar-se-iam por não ter nenhuma dimensão educativa e, sobretudo, em relação a gênero, como se nascêssemos possuidores de um determinado gênero, não existindo nada que construa/reforce/permeie as aprendizagens. Porém, de acordo com as observações realizadas, identifiquei como acontecem aprendizagens generificadas no recreio. Esses aspectos foram desenvolvidos mais detalhadamente na dissertação (Wenetz, 2005).

7. As traduções deste autor são de minha responsabilidade. 
primeira escolha foi de um local para realizar a observação, ou seja, uma escola. Fazia pouco tempo que eu estava na cidade ${ }^{8}$ e desconhecia tanto suas características quanto algum local para realizar minha pesquisa. Em diferentes referências bibliográficas (Winkin, 1998; Knauth, et al., 2000; Taylor et al., 1996), recomenda-se, como um primeiro passo importante da pesquisa etnográfica, a escolha do lugar onde vai ser realizada, incluindo-se todas as possíveis dificuldades que possam acontecer, como, por exemplo, a forma como se dá a entrada do pesquisador no campo, como se rompe com a imagem oficial que o grupo deseja projetar, como se conhecem os fatos não oficiais, como se controlam os informantes; o que se observa; como se registra e algumas estratégias para minimizar essas situações.

$\mathrm{Na}$ tentativa de definir um local para pesquisa, uma professora da universidade indicou um professor responsável pela disciplina dos estágios docentes. Ao apresentar meu projeto para ele, interessei-me pela escola em que ele atuava, por sua frequência naquele espaço em alguns dias da semana. $\mathrm{O}$ professor estaria no local em alguns dias e facilitaria meu ingresso, sem muitos problemas. Peguei o ônibus indicado e, depois de uma hora de viagem, estava na zona sul da cidade. Essa parte da cidade, eu não conhecia. Ao chegar, percebi um lugar muito tranquilo e bem diferente da zona central, local onde eu morava. O bairro tinha muitas áreas verdes e muitas casas ajardinadas, onde era possível ouvir pássaros cantando.

Nos últimos anos, toda essa região teve um crescimento importante na cidade, desenvolvendo-se não só construções de casas, mas também de edifícios residenciais e centros comerciais, e ampliando-se ruas e avenidas, como, por exemplo, a avenida central perto da escola, que aumentou praticamente três vezes seu tamanho. Os/as alunos/as que frequentam essa escola são de bairros mais distantes, mas que pertencem à região. A maioria dos/as alunos/as vem a pé para a escola; muitos/as deles/as vão e voltam sozinhos/as ou em grupos de irmãos ou vizinhos. Alguns contam com o transporte escolar, que é pago pelos pais, para ir à escola e voltar para casa.

O ingresso na escola não foi muito difícil. O professor da universidade apresentou-me à diretora. Não fui apresentada aos/as professores/as, aos/as funcionários/as e aos alunos/as; no entanto, comecei a circular pelo local, iniciando minha negociação com as pessoas?. Como já tinha o objetivo de observar o pátio da escola, fiquei observando as aulas dos/das estagiários/as de educação física. Participava de algumas reunióes desse grupo e vestia roupas esportivas, de modo que, assim, facilmente poderia ser confundida como uma estagiária da universidade, uma vez que a escola possuía convênios com a UFRGS para aulas de educação física nas séries

8. Só dois meses.

9. Com o transcorrer da pesquisa, elaborei um consentimento informado, colocando nele minha relação com a universidade e as características da pesquisa, o qual foi assinado, em nível institucional, pela diretora do estabelecimento. 
iniciais. Isso, sem dúvida, foi uma estratégia de minha parte - conhecer o lugar e as pessoas, pelo menos 'de vista', antes de ser preciso esclarecer exatamente o que eu fazia lá. Assim, passei quase despercebida; digo "quase" porque, na realidade, estava lá, e as pessoas notavam a minha presença; algumas vieram perguntar se era estagiária, se era uma nova professora, se era mãe de algum aluno, etc.

Nesse sentido, Bogdan e Knop (1994, p. 128) recomendam que o pesquisador se vista de acordo com os códigos de vestuário implícitos: se você está em um local onde as pessoas se vestem informalmente, vista-se também de maneira informal — "vista-se de maneira que pareça apropriada a seu estatuto naquela situação". Assim, conforme as recomendaçōes do autor, vesti-me de maneira informal. Seguindo o modo de vestir usual da área de educação física, não me apresentava muito diferente dos outros adultos que circulavam nesse espaço, ficando misturada com o ambiente. Assim, as pessoas foram descobrindo aos poucos que eu não era uma estagiária, mas uma pesquisadora, pois, através do tempo e das conversas, eu me apresentava. Enfim, meu ingresso na escola foi muito simples e facilitado, especialmente pela acolhida da direção da escola e pela circulação paralela de algumas pessoas que não eram professores/as dentro do âmbito escolar (estagiários/as), o que permitiu que me misturasse sem muita dificuldade.

A primeira impressão que tive da escola foi de que tudo era muito tranquilo e ordenado, características que eu achei que seriam facilitadoras quando do meu contato com os/as alunos/as, além do fato de a escola estar localizada em um extremo da cidade, ou seja, mais distante das escolas centrais. Pressupus que pouca gente (alunos/as, estagiários/as, etc.) pedisse ingresso na escola para fazer observação, situação comum nas escolas do centro, que já não queriam muita gente em seus espaços.

Essas situações de campo parecem ser questôes simples, mas são muito importantes. Escolher um local onde tenhamos a liberdade de entrar e sair quantas vezes quisermos é um detalhe que pode tanto beneficiar a pesquisa quanto prejudicá-la, retornar em algum momento. A vantagem de uma pesquisa autorizada é que ela nos permite ficar livres de obrigaçóes de um participante normal, ou seja, podemos atuar como pesquisadores (Bogdan; Knop, 1994).

Resumindo, eu tinha conhecido o local com antecedência, tinha liberdade de acesso e aceitação pela comunidade escolar e fiquei livre de alguma obrigação além daquilo que eu devia realizar, que era minha pesquisa. Este fato foi positivo teoricamente, já que nunca tive uma função diversa, a menos que eu mesma solicitasse. Isso permitiu que me colocasse sempre como pesquisadora. Nesse sentido, procurei não assumir nenhuma outra responsabilidade, pois, segundo Bogdan e Knop (1994, p. 117), isso poderia prejudicar minha mobilidade e liberdade na observação. O autor afirma que o pesquisador deve "evitar ter responsabilidades específicas [...] como ser colocado numa posição em que o pessoal escolar tenha 
muito controle sobre seu tempo e mobilidade". No entanto, essa possibilidade não diminuiu minha sensação de desconforto, incerteza e ansiedade.

Chegar à escola como estrangeira foi uma experiência muito interessante, pois essa condição provocava diferentes reaçōes nas pessoas e também em mim. Isso acontecia porque eu era uma dupla estrangeira - era uma pessoa 'de fora da escola' e, ainda, uma pessoa 'de fora do país'. Surgiam sensaçōes ou situaçōes que muitas vezes beiravam o estranho, como a curiosidade das crianças ante o fato de eu ser uma pessoa de fora de seu país - de certa maneira, uma viajante - e uma estranha na sua escola.

Nesse sentido, Rockwell (1987, p. 19) entende que a atividade da observação participante coloca o etnógrafo numa situação de exposição - "quase não há em nenhum lugar a exibição contínua de atividades tão estranhas como as que mostram os etnógrafos". O autor diz que essa situação se observa mais claramente com crianças, já que elas perguntam imediatamente quem somos e o que estamos fazendo lá.

Eu sempre me encontrei numa dupla situação, similar àquela que relata Fernanda Eugenio (2003, p. 209), contando como se encontrava dividida entre dois 'ofícios' do etnógrafo, que são a "observação participante e a sempre perseguidaembora-inatingível tentativa de adotar o ponto de vista do nativo". A observação participante exigia que eu olhasse e observasse aqueles que também estariam me olhando e observando. O segundo ofício, o ponto de vista do nativo, no meu caso, diferenciando-se da autora, implicava a impossível tarefa de estar no seu mundo, já que, por mais que eu pretendesse, não seria nem criança, nem brasileira.

Foi assim, como pesquisadora estrangeira, inserindo-me no quotidiano de uma escola brasileira, que fui definida, por várias crianças dessa escola, com idades diferentes e em distintas situaçōes, como "japonesa, italiana, espanhola, argentina, uruguaia"; também por "espiã, professora, estagiária, tia, professora comprida que fala enrolado, estranha", ou simplesmente por "amiga".

Aqui tento responder uma pergunta que todas as pessoas me fizeram, ao saber de uma mulher sozinha fora de seu país. Incluída entre essas pessoas, estava a diretora da escola, surpresa pelo fato de eu estar realizando meu mestrado numa universidade federal brasileira: "como você veio parar aqui?". De certa maneira, eu representei, para crianças, funcionárias/os e professores/as, o diferente, o desconhecido, o incerto, o desconcertante, o estranho, o estrangeiro, o viajante ${ }^{10}$.

10. A ideia da viagem implica algumas considerações. "Viajar" é definido no dicionário como o ato ou efeito de ir de um lugar a outro razoavelmente distante, deslocar-se, ou seja, um deslocamento que sugere uma ideia de transição no tempo e no espaço. Louro (2004, p. I4) entende que, ao falarmos de viagem, podemos fazer referência também a "uma distância cultural, naquela que se representa como diferença, naquele ou naquilo que é estranho, no 'outro' distanciado e longínquo". 
Além desses aspectos, também fiquei confusa quanto à possibilidade de intervir ou não ante algum acontecimento que supostamente não deveria acontecer no pátio, como, por exemplo, uma briga. Lembro que, no começo, não deixava de interferir - primeiro, porque eu mesma considerava essas situaçóes violentas; segundo, porque pensava que, se alguém estivesse me observando e eu não interferisse, essa pessoa poderia me questionar: "o que você está fazendo aqui?!"

Neste ponto, várias reflexões podem ser feitas. Embora alheia às atividades curriculares da escola, eu era uma professora, adulta, mulher, num espaço onde se supõe que se cuide das crianças, atribuiçōes socialmente 'esperadas' de uma professora e tradicionalmente correspondentes à mulher: como poderia eu explicar que "aquilo aconteceu, mas eu decidi não intervir"?

Depois de um tempo, optei por não intervir, e o que aconteceu foi que alguém apareceu detrás de mim para intervir e controlar a situação. Afinal de contas, minha função não era cuidar das crianças, embora eu fosse uma pessoa adulta/professora. A não intervenção permitia-me observar o desenvolvimento dos acontecimentos e construir uma parceria maior com as crianças, já que eu não ocupava a posição de sentenciar o que estava 'errado' e não era permitido fazer e o que era certo. Tudo isso me possibilitou uma maior identificação afetiva com elas.

\section{caminho das mudanças}

$\mathrm{Na}$ primeira etapa de campo, minhas observaçōes foram mais intuitivas e optei por não registrar tudo o que acontecia. Nesse momento, o objetivo era familiarizar-me com o local e com as pessoas, tentando especificar meu foco de trabalho, pois, segundo Winkin (1998), nessa fase do trabalho de campo, nós, como pesquisadores, não estamos fazendo nada além de visualizar alguma coisa, embora tenhamos a expectativa de observar algo particular dentro do geral. Essa etapa durou aproximadamente três meses.

Uma segunda etapa de observaçôes aconteceu no segundo semestre de 2003. Realizei observaçōes durante três meses, com a frequência de uma visita semanal, seguida da observação participante de três a quatro vezes por semana a partir de março de 2004 até dezembro do mesmo ano. Nesse período, participei de diferentes momentos da rotina escolar, ingresso e egresso da instituição, conselhos de classe, festas, passeios, aulas de educação física no pátio e aulas das outras disciplinas em sala de aula, reunião de estagiários/as de educação física, lanche dos/as alunos/as e recreios.

Dessa maneira, a relação estabelecida entre a pesquisadora e a população escolhida deu-se na forma de observação participante, com o objetivo de a pesquisadora tornar-se parte do contexto de pesquisa, pois a observação participante apontava para a importância de captar toda a gama de situaçóes ou fenômenos que 
aconteciam no grupo social (Becker, 1997). A observação participante apresenta a vantagem de permitir que o pesquisador chegue mais perto das experiências diárias dos sujeitos, observando os significados que atribuem a seus comportamentos (Stigger, 2002).

Depois da escolha do local, minhas primeiras decisões metodológicas foram a definição do grupo que seria observado e também o momento de observação do recreio escolar. Em relação a esses aspectos, em 2002, primeiro ano em que observei o ambiente, o recreio da primeira à oitava série era conjunto. Portanto, a quantidade de crianças no mesmo espaço impossibilitava a observação de algum grupo. Minha primeira sensação ao chegar ao espaço de pesquisa era de desassossego, caos, inquietação, ansiedade. Muitas vezes, angustiada, perguntava-me: como e de que modo iria 'ler, olhar' para aquele espaço? 'O que, quando' ou 'com que critérios' eu observaria esse espaço, onde muita coisa acontecia ao mesmo tempo?

Apesar disso, nas minhas observações, foi marcante o momento em que passei de uma observação a uma observação participante, quando comecei a falar com as crianças, e não só observá-las. Nesse momento, um mundo de conversas, perguntas e informaçóes colocou-se diante de mim. De repente, vi-me diante do que é chamado de "bola de neve", quando começamos a conversar com um número pequeno de pessoas e, depois de ter um vínculo, pedimos que nos apresentem a outras (Taylor, 1996, p. 41). Mesmo sabendo que iria acontecer, surpreendi-me, pois fiquei pelo período de uma semana sentindo-me como uma 'atração turística da escola'; não precisei pedir que me apresentassem a outras pessoas, pois o sotaque ajudou nesse momento. Desse modo, a novidade (da estrangeira) se espalhou pela escola, e muitas crianças de diferentes idades vinham me ouvir falar e me fazer perguntas. Depois desse tempo, isso foi mudando; à medida que fui me misturando no seu quotidiano, deixei essa posição de turista.

Segundo Bauman (1998, p. 114), turistas "realizam a façanha de não pertencer ao lugar que podem estar visitando", isto é, podem estar simultaneamente dentro-fora. Mas o turista guarda uma distância, ele "veda a distância de se reduzir à proximidade" (Ibid.). O autor agrega que os turistas se sentem seguros, podendo mudar a direção ou abandonar um local quando começam a sentir falta da segurança ou quando a finalidade do prazer deixa de estar presente.

Outras características que chamaram minha atenção foram festas, comemorações, a vestimenta e a exposição do corpo na escola. Isso porque, no meu país, professores/as, alunos/as e funcionários/as comparecem na instituição com um guarda-pó, geralmente branco, que tapa todo o corpo ou a maior parte dele, já que chega até os joelhos. A exposição do corpo chamou minha atenção — nos meses de calor, permitia-se o uso de roupas mais soltas e curtas por parte das pessoas que circulavam pela instituição.

Mas por que achava estranho tudo isso? Por que o corpo chamava a minha atenção? Será que eu tinha aprendido que o corpo deveria ser deixado na porta 
da escola? bell hooks ${ }^{11}$ (1999, p. 115) entende que "o mundo público da aprendizagem institucional é um lugar onde o corpo tem de ser anulado, tem que ser despercebido".

Um corpo diferente, estranho, alheio e estrangeiro - quem era diferente, as crianças ou eu? Isso dependia de quem estivesse olhando quem, de quem estivesse observando quem. Enfim, tratava-se de uma relação de ida e volta em que muitas vezes me perguntei: tudo isso é estranho para quem? Como diz Larrosa (2002, p. 84), "não será o estrangeiro o que nos faz estrangeiros e, justamente por isso, o que nos permite ser nós mesmos?”.

Depois dessa etapa de apresentação, passei a brincar com as crianças, o que abriu caminho para um investimento diferente e vínculos sociais a serem estabelecidos entre nós. Participando desse modo, eliminei uma possível associação de minha figura com a de autoridade, criando espaços para a parceria e possibilitando que as crianças atuassem com maior naturalidade, já que "é difícil que a criança aceite um adulto como igual, embora seja possível que o tolere como membro de um grupo de crianças" (Bogdan; Knop, 1994, p. 126).

Apesar dessas estratégias, a decisão de observar o recreio criou mais tensão do que esperava. O desassossego continuava. Depois, em 2003, já priorizava a observação dos grupos da primeira à quarta série, sendo ainda muito amplo o foco de observaçãa ${ }^{12}$. Com o passar do tempo, aquela ansiedade foi diminuindo. Comecei a ver mais prazer naqueles atos, situaçôes ou brincadeiras que, quando 'olhava de fora', pareciam violentos ou rebeldes. Agora, não me espantavam, e tinha que conter minha alegria ao observar situaçóes em que as crianças realizavam brincadeiras diferentes ou mostravam alguma resistência.

Por essas razões, decidi escolher duas turmas. Elas não foram definidas a priori. Seriam aquelas que chamassem minha atenção em relação à minha pergunta de pesquisa. Foram elas uma segunda e uma terceira série, que já tinha observado no ano anterior e que vivenciavam ou apresentavam situaçôes interessantes em relação ao gênero. Mesmo com essas providências, estava com dificuldade de analisar

1।. Toda vez que eu citar essa autora, seu nome estará em minúscula, pois ela mesma o escreve desse modo.

12. Isto acontecia porque eram 360 crianças no mesmo espaço num período de quinze minutos. No ano de 2004, os horários do recreio mudaram: dos 30 minutos com todos os alunos juntos, agora os primeiros 15 minutos se destinavam aos estudantes maiores (da quinta série até a oitava série), e os 15 minutos seguintes seriam reservados para as crianças da primeira à quarta série. Levei um tempo para perceber isso no pátio. Primeiro, porque a própria observação demandou que eu adotasse o uso de um relógio, hábito que até então não fazia parte do meu quotidiano; segundo, porque, ao tocar a sirene de troca dos recreios, muitos/as alunos/as da área (ou alunos/as maiores) não se mobilizavam para sair do pátio e acabavam ficando muito mais tempo que o seu horário de recreio, ocupando o tempo dos/as outros/as alunos/as. Isso ocorria ora sem motivo aparente, ora porque não tinham aula, ora porque tinham aula no pátio. 
esse contexto tão complexo. Então, foi-me sugerido por um professor da universidade um movimento diferente: entrar em sala de aula e acompanhar um pouco as crianças na sua rotina escolar para estabelecer as diferenças entre um espaço e outro e poder conhecê-las melhor. Isso aconteceu sem muitas dificuldades. Com o consentimento da diretora e das professoras, comecei a participar da jornada completa das crianças na escola.

Fiquei duas semanas acompanhando as aulas e, apesar de tentar não ser muito inconveniente, surgiu uma situação interessante: uma conversa que estabeleci com a supervisora da escola. Ela me perguntou quantos dias eu ficaria dentro da sala de aula, uma vez que "as professoras não gostam muito que fique alguém olhando" (D. C. $\left.{ }^{13} 4 / 10 / 04\right)$. No transcorrer do tempo, esse acontecimento foi mínimo ou de uma importância menor, mas repetiu-se duas vezes mais na mesma semana. Então, pude perceber que observar no pátio da escola, como estava fazendo há muito tempo, tinha, para o grupo de docentes da escola, uma conotação muito diferente de observar em sala de aula, apesar de eu não focalizar o trabalho pedagógico. De fato, no pátio, eu 'não incomodava ninguém', já que, por um lado, não era um lugar que merecesse tanto respeito ou importância quanto a sala de aula, a sala de professores/as. Por outro lado, apesar de especificar que o meu interesse não era observar ou avaliar o trabalho do/a docente, mas 'conhecer' as crianças, os/as professores/as sentiam-se avaliados/as, pois eram 'os/as responsáveis'. Com isso, posso entender que o recreio é um momento menor, sem 'responsáveis' definidos a priori, e o pátio da escola é um espaço não importante. Ainda, esses acontecimentos destacam que a aula de educação física parece ser necessariamente pública e/ou menos respeitável que as outras áreas de conhecimento, portanto, pode ser observada sem dificuldades.

Enquanto realizava minhas observações em sala de aula, encontrei a pesquisa de Tânia Cruz (2004). A leitura desse trabalho encorajou-me a utilizar um instrumento metodológico de que tinha quase desistido pela falta de referencial sobre o uso de entrevistas com crianças. Passei, então, a realizar entrevistas semiestruturadas, que se conformam com um roteiro de perguntas que poderiam ser modificadas no processo de diálogo com o/a informante/colaborador/a. As questōes organizam-se em torno de uma série de temas que possibilitam a formulação de novas perguntas com o decorrer da entrevista, o que oferece a liberdade ao/à entrevistado/a para argumentar (Burguess, 1997).

Procedi dessa forma, mesmo conhecendo as recomendações de Martine Delfos (2001), que entende que não se devem realizar entrevistas com crianças menores de dez anos porque somente a partir dessa fase as crianças têm uma maior liberdade para expressar-se ante as perguntas do/a entrevistador/a. Apesar de suas recomen-

13. D.C.: Diario de Campo.

Pro-Posições, Campinas, v. 22, n. 2 (65), p. 133-149, maio/ago. 2011 
dações, decidi arriscar-me e realizei a maioria das entrevistas com crianças entre 8 e 9 anos (segunda e terceira série), as quais não mostravam nenhuma dificuldade em manter a conversação.

Realizei as entrevistas de um modo artesanal (Becker, 1997), o que me permitiu uma maior liberdade. Segundo Luc Albarello et al. (1997, p. 96), a entrevista é uma técnica, mas, "mais do que uma técnica, é uma arte", destacando-se que, por mais que seja superficial como um meio de obter informações, é sumamente complexa, ainda mais se desenvolvemos essa atividade com crianças. Realizei as entrevistas com duas crianças (na terceira série) ou três crianças (na segunda série) para não dificultar a transcrição e para não constrangê-las. Chamei uma criança, e esta, por sua vez, chamava um colega de sua preferência. Dessa maneira, evitavamse situaçôes de briga durante a entrevista e também diminuíam as possibilidades de constrangimento diante de algumas perguntas.

Antes dessa etapa, decidi aplicar outra estratégia que consistia em entrar na sala de aula e apresentar as perguntas para todo o grupo, ouvindo as respostas e apontando algumas considerações no meu caderno. Tal estratégia foi adotada por vários motivos. Um deles foi a possibilidade de as crianças conhecerem as perguntas e não se sentirem 'surpreendidas'. Outro, foi para que não ficassem ansiosas com a participação ou para que pudessem decidir se queriam participar - explicitei que só precisaria conversar à parte com elas porque eram muitas, e eu não conseguiria registrar tudo para meu trabalho.

Outra razão, ainda, foi diminuir a inibição durante as entrevistas, que planejava fazer em outro local e com uma possível gravação. Também esclareci que aqueles que não quisessem participar poderiam colocar seu nome numa lista, e eu não os chamaria - só iriam as crianças que quisessem, já que uma das características da entrevista é deixar o/a entrevistado/a à vontade.

Para a transparência do procedimento, elaborei as perguntas e mostrei-as para a direção da escola, pois percebi seu interesse por aquilo que seria conversado na sala. Tive que realizar as entrevistas num curto período de tempo, pois o início do calendário das provas escolares, já definido, aproximava-se e não desejava prejudicar nenhuma criança. Para minha grata surpresa, a maioria das crianças quis participar. Com isso, de 59 crianças, 58 participaram. Um único menino não quis participar porque, conforme relatou, "estava com muita vergonha" 14 .

Cada dupla de crianças era entrevistada por cerca de 30 minutos em um es-

14. Em relação ao silêncio do menino, interpretei como uma característica pessoal, e não como algo relativo à pesquisa em si, até porque demonstrou curiosidade depois de não ter participado. Procurei respeitar seu silêncio, entendendo que algumas crianças não falam, mas, segundo Zelia Fabri (2002, p. 9), "de alguma maneira, todas as crianças falam". No caso desse menino, interpretei como uma preocupação pessoal em realizar as tarefas de sala de aula, articulada com a vergonha de expor-se. 
paço predeterminado, normalmente uma sala não utilizada por outras turmas de alunos/as, e a conversa era gravada. Coloquei lanches para as crianças comerem, com o objetivo de deixá-las à vontade, tentando tornar o momento e o ambiente o mais informal possível, pois, oferecendo a possibilidade de elas e eu comermos juntos, repetia uma atividade que realizávamos no recreio, além de considerar que as entrevistas seriam feitas em horários em que muitos/as dos/as alunos/as deveriam estar no refeitório lanchando. Cabe destacar que isso não foi uma barganha com as crianças no sentido de dar os salgadinhos em troca das falas; ao contrário, entendi que comer (atividade que faziam no recreio, e não em sala de aula) talvez pudesse deixá-las menos nervosas ao realizar uma atividade que lhes era estranha.

O fato de ter gravado as conversas foi positivo, apesar da ansiedade demonstrada pelas crianças, pois muitas delas nunca tinham ouvido sua voz gravada. Por isso, falavam devagar para que a gravação ficasse nítida e ficavam muito curiosas para ouvir suas próprias vozes. Expliquei para as crianças que, em nosso caso, a entrevista era um acontecimento único e que não teríamos oportunidade de repeti-la. Delfos (2001) entende que isso deve ser esclarecido para que não se alimentem falsas expectativas, uma vez que, ante uma conversa exitosa, a criança pode sentirse aliviada e querer retornar quando, às vezes, isso não é possível. Os/as alunos/as mostraram-se à vontade, e fui adquirindo uma maior confiança deles/delas com o passar do tempo.

A possibilidade de realizar as entrevistas colocou-me numa nova situação: o que fazer com os nomes das crianças? Deixava os nomes verdadeiros ou os omitia? Essa simples decisão pode-se tornar uma dificuldade em pesquisas com crianças e levar a sérios problemas, não só acadêmicos, mas legais. Minha estratégia para sair do impasse foi levar a situação à direção da escola, já que, por mais que eu considerasse cada criança como um sujeito de minha pesquisa, não seriam elas que assinariam um consentimento ético, mas seus pais ou as pessoas adultas responsáveis por elas. Ainda, como poderia eu preservá-las, se o texto fosse publicado? Como evitar a exposição? Será que eu tinha esse direito?

A saída do campo, que poderia ter ocorrido em junho ou julho, acabou ocorrendo no início de dezembro de 2004, pois meu vínculo afetivo com a escola foi tão grande que eu tinha muita dificuldade para deixar aquele espaço. Devido às características informais do espaço observado, decidi ir embora da mesma forma que cheguei: sem grandes cerimônias nem avisos; simplesmente fui espaçando minhas visitas, diminuindo a quantidade de tempo de cada uma, até que deixei de ir. Bogdan e Knop (1994, p. 144) entendem que "esta transição é psicologicamente eficaz tanto para os investigadores como para os sujeitos". Conversei novamente com a diretora do estabelecimento e fui-me ausentando do quotidiano escolar, às vezes conversando com algum aluno ou funcionária, até não estar mais presente. 


\section{Para concluir}

Pretendi, neste artigo, apresentar um pouco do meu processo metodológico de pesquisa na escola, descrevendo a etnografia com crianças a partir do olhar de uma estrangeira, num sentido duplo, relatando as diferentes escolhas e decisóes realizadas e, simultaneamente, trazendo algumas consideraçóes sobre a etnografia e sobre as percepções de um estrangeiro. Também busquei provocar uma articulação entre a etnografia e as crianças, ressaltando algumas dificuldades determinadas pela quase ausência de trabalhos que relacionassem essas áreas. Tais dificuldades não diminuíram o tom de desafio do trabalho. Há grande riqueza nessa articulação teórica no convívio com as crianças no seu quotidiano escolar, o que me possibilitou 'conhecê-las' como sujeitos participantes e produtores de sua cultura.

Destaco a seguir, de maneira muito sucinta, alguns dos resultados da pesquisa. Na turma da terceira série, foi possível observar a institucionalização da heterossexualidade como norma: um menino que brinca só com as meninas é considerado homossexual num sentido pejorativo. Nesse mesmo grupo, observei como algumas crianças (tanto meninas quanto meninos) atravessam as fronteiras do gênero, realizando brincadeiras que são consideradas do outro gênero; apesar disso, não são tratadas depreciativamente pelos colegas porque essas crianças não colocam em xeque a norma da heterossexualidade, ou seja, embora realizem as brincadeiras do outro gênero, permanecem com sua masculinidade, no caso de meninos, e sua feminilidade, no caso de meninas.

No grupo da segunda série, observei como as meninas e os meninos "devem ser". Suas "classificaçōes" já constituem parte do seu quotidiano, então, é "normal que a/o menina/o seja assim". Observei também como meninas e meninos saem desses padrōes considerados "naturais".

À medida que isso acontece, novas estratégias de regularização aparecem. Meninas são chamadas de 'barangas', e meninos devem ser cavalheiros, mas não covardes, nem 'bebezinhos da mamãe'. Assim, os meninos têm que, de maneira repetida e insistente, reforçar sua heterossexualidade, devendo 'ser machos' e definindo-a através de quem é mais forte e mais rápido.

Nesse sentido, meninos e meninas "classificam" brincadeiras como de meninas ou de meninos. As crianças que tiveram alguma experiência realizando uma brincadeira do outro gênero têm, posteriormente, maiores 'dificuldades' em classificar uma brincadeira como exclusivamente de meninos ou de meninas, salvo as brincadeiras com bonecas, que sempre são definidas como 'de meninas', e as lutas e/ou futebol, que, na maior parte das vezes, são definidas como 'de meninos'.

Isso nos leva a considerar que as brincadeiras - que parecem ter só um caráter prazeroso - têm também uma produção dos sujeitos disciplinados por viverem dentro de um contexto social e histórico, onde assumem um jeito de ser menino 
e um jeito de ser menina, enquadrados nos padróes que sua sociedade considera como normais. Nesse contexto cultural, a criança produz e é produzida através das brincadeiras.

\section{Referências bibliográficas}

Albarello, L. et al. Práticas e métodos de investigação em Ciências Sociais. Portugal: Gradiva, 1997.

BAUMAN, Z. O Mal-Estar da Pós-modernidade. Rio de Janeiro: Jorge Zahar Editora. 1998.

BECKER, S. H. Métodos de pesquisa em Ciências Sociais. São Paulo: Hucitec, 1997. p. 178.

BOGDAN, R.; KNOP, S. B. Investigação qualitativa em Educação: uma introdução à teoria e aos métodos. Portugal: Porto, 1994.

BELL HOOKS. Eros, erotismo e o processo civilizatório In: LOURO, Guacira (Org.). O corpo educado: pedagogias da sexualidade. Belo Horizonte: Autêntica, 1999.

BOYLE, E. D.; MARSHALL, L. N.; ROBESON, W. W.Gender at play: fourth-grade girls and boys on the playground. American Behavioral Scientist. n. 24, p. 1326, 2003. Disponível em: <www.emabs.sagepub.com> (Capes). Acesso em: fev. 2008.

BURGUESS, R. G. A pesquisa de terreno — uma introdução. Portugal: Celta, 1997.

CRUZ, T. Meninas e meninos no recreio: gênero, sociabilidade e conflito. Tese (Doutorado) - Faculdade de Educação, Universidade de São Paulo, São Paulo, 2004.

DELFOS, M. F. Me escuchas? Como conversar con niños de cuatro a doce años. Netherlands: Bernard Van Leer Foundation, 2001.

EUGENIO, F. De como olhar onde não se vê: ser antropóloga e tia em uma escola especializada para crianças cegas. In: VELHO, G.; KUSCHNIR, K. (Org.). Pesquisas urbanas: desafios do trabalho antropológico. Rio de Janeiro: Jorge Zahar, 2003.

EPSTEIN, D.; KEHILY, M.; MAC AN GAILL, M.; REDMAN, P. Boys and girls come out: making masculinities and feminities in school playgrounds. Men and masculinities, n. 4, p. 158, 2001. Disponível em: <www.emabs.sagepub.com> (Capes). Acesso em: fev. 2008.

DEMARTINI, Z. B. Fabri. Infância, pesquisa e relatos orais. In: FARIA, A. L. G. de; DEMARTINI, Z. B. F.; PRADO, D. P. (Org.). Por uma cultura da infância: metodologias de pesquisa com crianças. Campinas, SP: Autores Associados, 2002.

GEERTZ, C. A interpretação das culturas. Rio de Janeiro: Guanabara Koogan, 1989a. p. 324.

GEERTZ, C. Estar lá, escrever aqui. Diálogo, São Paulo, v. 22, n. 3, p. 58-63, 1989b.

GOODWIN, M. H. Exclusion in girls' peer groups: ethnographic analysis of language practices on the playground. Humam Development, v. 45, n. 6, nov./dez. 2002, p. 392-415. Disponível em: <www.emabs.sagepub.com> (Capes). Acesso em: fev. 2008. 
KELLE, H. Gender and territoriality in games played by nine-to twelve-year-old schoolchildren. Journal of Contemporary Ethnography, v. 29, n. 2, p. 164-197, 2000. Disponível em: <www.emabs.sagepub.com> (Capes). Acesso em: fev. 2008.

KNAUTH, D.; CERES, V.; AGRA HASSEN, M. Pesquisa qualitativa em saúde. Porto Alegre, RS: Tomo, 2000. p. 133.

LARROSA, J. Para qué nos sirven los extranjeros? Educação \& Sociedade. Revista Quatrimestral de Ciência da Educação. Ano XXIII. N. 79. Agosto. 2002.

LOURO, G. L. Corpo, escola e identidade. Educação \& Realidade, Porto Alegre, v. 25, n. 2, p. 59-76, jul./dez. 2000.

LOURO, G. L. Um corpo estranho: ensaios sobre sexualidade e teoria queer. Belo Horizonte: Autêntica, 2004.

MEYER, D. Gênero e educação: teoria e política. In: LOURO, G.; NECKEL, J. F.; GOELLNER, S. V. (Org.). Corpo, gênero e sexualidade: um debate contemporâneo na Educação. Petrópolis: Vozes, 2003.

NICHOLSON, L. Interpretando o gênero. Estudos Feministas, v. 8, n. 2, p. 9-42, 2000.

PORTO ALEGRE. Memória dos Bairros. Belém Velho. Prefeitura Municipal de Porto Alegre, RS, 1994. p. 98.

PORTO ALEGRE. Memória dos Bairros. Restinga. Prefeitura Municipal de Porto Alegre, RS, 1997. p. 22.

RONALD, E. "If you don't kiss me, you're dumped": boys, boyfriends and heterosexualized in the primary school. Educational Review, v. 55, n. 2, p. 179-194, jun. 2003. Disponível em: <www.emabs.sagepub.com > (Capes). Acesso em: fev. 2008.

ROCKWELL, E. Reflexiones sobre el proceso etnográfico (1982-85). México: Centro de Investigación y de Estudios Avanzados del Instituto Politecnico Nacional. Departamento de Investigaciones Educativas, 1987. p. 87.

SWAIN, J. The role of sport in the construction of masculinities in English independent Junior school. Sport, Education and Society, v. 11, n. 4, p. 317-335, nov. 2006. Disponível em: <www.emabs.sagepub.com> (Capes). Acesso em: fev. 2008.

STIGGER, M. P. Esporte, lazer e estilos de vida: um estudo etnográfico. Campinas, SP: Autores Associados; São Paulo: Editorial Colégio Brasileiro de Ciências do Esporte (CBCE), 2002. p. 278. Coleção Educação Física e Esportes.

TAYLOR, S. J. Y; BOGDAN, R. Introducción a los métodos cualitativos de investigación. La búsqueda de significados. Barcelona: Paidós, 1996.

WENETZ, I. Gênero e sexualidade nas brincadeiras do recreio. Dissertação (Mestrado) - Programa de Pós-Graduação em Ciências do Movimento Humano, Escola de Educação Física (EsEF), Universidade Federal do Rio Grande do Sul (UFRGS), 2005.

WINKIN, Y. A nova comunicação: da teoria ao trabalho de campo. Campinas, SP: Papirus, 1998. 
WOODS, P. La escuela por dentro. La etnográfica en la investigación educativa. Barcelona: Paidós, 1995. p. 217. Temas de Educación.

Recebido em 18 de março de 2009 e aprovado em 30 de abril de 2010. 